\title{
The Danish Cerebral Palsy Follow-up Program
}

This article was published in the following Dove Press journal:

Clinical Epidemiology

25 October 2016

Number of times this article has been viewed

\section{Helle Mätzke Rasmussen ${ }^{1,2}$ \\ Kirsten Nordbye-Nielsen ${ }^{3}$ \\ Bjarne Møller-Madsen ${ }^{3}$ \\ Mette Johansen ${ }^{4}$ \\ Niels Ellitsgaard ${ }^{5}$ \\ Charlotte Reinhardt \\ Pedersen $^{6}$ \\ Gija Rackauskaite ${ }^{7}$ \\ Henriette Engberg, 8 \\ Niels Wisbech Pedersen ${ }^{2}$ \\ 'Department of Pediatrics, The Danish Cerebral Palsy Follow-up \\ Program, Lillebaelt Hospital, Kolding, \\ ${ }^{2}$ Department of Orthopedic Surgery \\ and Traumatology, Institute of \\ Clinical Research, Odense University \\ Hospital, University of Southern \\ Denmark, Odense, ${ }^{3}$ Department of \\ Children's Orthopaedics, Aarhus \\ University Hospital, Institute of \\ Clinical Research, Aarhus University, \\ Aarhus, ${ }^{4}$ Department of Pediatrics, \\ Aalborg University Hospital, Aalborg, \\ ${ }^{5}$ Department of Orthopedic Surgery, \\ Hvidovre University Hospital, \\ Hvidovre, ${ }^{6}$ Department of Pediatrics, \\ North Zealand Hospital Hilleroed, \\ Hilleroed, ${ }^{7}$ Department of Pediatrics, \\ Aarhus University Hospital, \\ Aarhus, ${ }^{8}$ Research Unit of Clinical \\ Epidemiology, Institute of Clinical \\ Research, University of Southern \\ Denmark, ${ }^{9}$ Centre for Clinical \\ Epidemiology, Odense University \\ Hospital, Odense, Denmark}

Correspondence: Helle Mätzke Rasmussen

Department of Pediatrics, The Danish

Cerebral Palsy Follow-up Program,

Lillebaelt Hospital, Skovvangen 2-8, 6000

Kolding, Denmark

Tel +452018 0919

Email helle@cpop.dk
Aim of database: The Danish Cerebral Palsy Follow-up Program is a combined follow-up program and national clinical quality database that aims to monitor and improve the quality of health care for children with cerebral palsy (CP).

Study population: The database includes children with $\mathrm{CP}$ aged $0-15$ years and children with symptoms of CP aged $0-5$ years.

Main variables: In the follow-up program, the children are offered examinations throughout their childhood by orthopedic surgeons, physiotherapists, occupational therapists, and pediatricians. Examinations of gross and fine motor function, manual ability, muscle tone, passive range of motion, use of orthotics, and assistive devices are performed once a year; radiographic examination of the hips is planned based on the child's age and gross motor function; and the diagnosis is performed once before the age of 5 years. Six indicators were developed based on scientific literature and consensus in the steering committee, and their calculation is based on the following four main variables: radiographic examination of the hip, gross motor function, manual ability, and diagnosis.

Descriptive data: The 2014 annual report includes results of the quality indicators in three of five regions in Denmark comprising 432 children with CP, corresponding to a coverage of $82 \%$ of the expected population.

Conclusion: The Danish Cerebral Palsy Follow-up Program is currently under development as a national clinical quality database in Denmark. The database holds potential for research in prevalence, clinical characteristics of the population, and the effects of prevention and treatment.

Keywords: cerebral palsy, clinical quality database, hip surveillance

\section{Aim of database}

The Danish Cerebral Palsy Follow-up Program (CPOP) is a combined follow-up program and a national clinical quality database that includes children with cerebral palsy (CP) aged $0-15$ years and children with $\mathrm{CP}$-like symptoms aged $0-5$ years. The objective of the follow-up program is to prevent complications of $\mathrm{CP}$ and promote the use of standardized examinations by orthopedic surgeons, pediatricians, occupational therapists, and physiotherapists. The clinical quality database includes data obtained from the examinations and aims to document, monitor, and improve the quality of health care for children with CP in Denmark.

\section{Study population}

$\mathrm{CP}$ is the most common congenital motor disability in childhood with a prevalence of 2.1-3.0/1,000 live births. ${ }^{1}$ According to the Surveillance of Cerebral Palsy in Europe submit your manuscript | www.dovepress.com Dovepress http://dx.doi.org/1 0.2147/CLEP.S99474
Clinical Epidemiology 2016:8 457-460 (Thematic series on clinical quality databases in Denmark) 457 (c) (i) (9) 2016 Rasmussen et al. This work is published and licensed by Dove Medical Press Limited. The full terms of this license are available at https://www.dovepress.com/ (c) ${ }_{\mathrm{BY}} \mathrm{NC}$ terms.php and incorporate the Creative Commons Attribution - Non Commercial (unported, v3.0) License (http://(creativecommons.org/licenses/by-nc/3.0/). By accessing the work you hereby accept the Terms. Non-commercial uses of the work are permitted without any further permission from Dove Medical Press Limited, provided the work is properly attributed. For permission for commercial use of this work, please see paragraphs 4.2 and 5 of our Terms (https://www.dovepress.com/terms.php). 
definition, CP is "a group of permanent but not unchanging disorders of movement and/or posture and motor function, which are due to a non-progressive interference, lesion or abnormality of the developing/immature brain."' Although the brain lesion is nonprogressive, the neuromusculoskeletal and movement-related functions do change and can cause limitations in relation to activity and participation. ${ }^{2}$

The diagnosis of CP can be categorized into four subtypes: spastic, dyskinetic, ataxia, and mixed form. ${ }^{2}$ The subtype is supplemented with a classification of motor function using the Gross Motor Function Classification System and the Manual Ability Classification System. ${ }^{3,4}$ Both systems are ordinal scales with five levels of function, representing clinically meaningful distinctions in motor function. Children at level I are the least disabled, although they may have limitations in advanced motor skills. Children at level V have the most severe motor disability. Their ability to perform independent movements and functions is limited even with the use of assistive technology.

Children with CP are in need of continuous follow-up and treatment throughout childhood. In Denmark, the responsibility for health care for children with $\mathrm{CP}$ is shared between five regions and 98 municipalities. The regions are responsible for the hospitals and thus the interventions by orthopedic surgeons and pediatricians. The municipalities are responsible for interventions by physiotherapists and occupational therapists, who are affiliated to a range of different institutions, such as rehabilitations centers, nurseries, and special needs schools.

\section{The follow-up program and national clinical quality database}

A follow-up program and database were developed $>20$ years ago in Sweden as a secondary prevention program to detect early signs of deterioration through standardized examinations performed by physiotherapists and occupational therapists once a year, orthopedic surgeons based on the child's age and gross motor function, and pediatricians once before the age of 5 years. ${ }^{5}$ Sweden, Norway, Scotland, and parts of Iceland and Australia now use the program or some modified versions. ${ }^{6}$

In Denmark, CPOP was started in the Region of Southern Denmark in 2010 and is currently under development as a national follow-up program and clinical database. CPOP is currently implemented for children born in 2003 or later in the Region of Southern Denmark and children born in 2008 or later in the Central Denmark Region, the Capital Region of Denmark, and the North Denmark Region.
The annual report from 2014 describes the quality of health care in three of five regions for 432 children with $\mathrm{CP}$, corresponding to a coverage of $82 \%$ of the expected population in the regions. The annual report will cover all the five regions of Denmark from 2017. CPOP is expected to be fully implemented in 2023, when children born in 2008 are 15 years of age. Approximately 125 children are diagnosed with CP every year, thus the CPOP follow up program expects to include 1,800 children when fully implemented.

The follow-up program will be a population-based service, including all children diagnosed with $\mathrm{CP}$ aged $0-15$ years and children with CP-like symptoms aged $0-5$ years. If the diagnosis is confirmed at the age of 5 years, the child continues to be enrolled in the follow-up program, and if the diagnosis cannot be confirmed, the child is dismissed from the program. All children participating in the program are registered in the CPOP database.

The examinations in the CPOP are offered throughout the childhood and should lead to early detection of complications, such as hip dislocation, scoliosis, and contractures of muscles and joints. ${ }^{6}$ The examinations are reported to the database by orthopedic surgeons, physiotherapists, occupational therapists, and pediatricians across regions and municipalities. The involved pediatric departments offer interdisciplinary consultations, where children, parents, and health care professionals meet and agree on future follow-ups and interventions.

\section{Main variables}

Pediatricians perform the initial evaluation for inclusion of children in CPOP. The examinations are planned based on the child's age and gross motor function as outlined in Table 1. The examinations can be completed at any time during the calendar year of follow-up.

Orthopedic surgeons are responsible for repeated radiographic examinations of the hip and spine, including measuring the degree of femoral head displacement. ${ }^{7}$

Physiotherapists or occupational therapists describe the child's gross motor function and manual ability using Gross Motor Function Classification System and Manual Ability Classification System. ${ }^{3,4}$ Furthermore, they perform a physical examination of the spine, muscle tone, passive range of motion, pain, mobility/transfer/positioning, and use of orthotics and assistive devices.

Pediatricians examine the child and confirm that the criteria for CP diagnosis are met. ${ }^{2}$ Furthermore, they describe the CP subtype, etiology, and other health conditions/ disabilities. 
Table I Assessments in The Danish Cerebral Palsy Follow-up Program that are reported to the database

\begin{tabular}{|c|c|c|}
\hline Profession & Assessment & $\begin{array}{l}\text { Time } \\
\text { points }\end{array}$ \\
\hline $\begin{array}{l}\text { Orthopedic } \\
\text { surgeons }\end{array}$ & $\begin{array}{l}\text { Radiographic examination of the hips } \\
\text { Radiographic examination of the spine }\end{array}$ & As needed ${ }^{a}$ \\
\hline $\begin{array}{l}\text { Physical and } \\
\text { occupational } \\
\text { therapist }\end{array}$ & $\begin{array}{l}\text { Gross motor function and manual ability } \\
\text { Functional mobility and fine motor function } \\
\text { Muscle tone } \\
\text { Passive range of motion } \\
\text { Spinal examination } \\
\text { Pain } \\
\text { Mobility/transfer/positioning } \\
\text { Orthotics } \\
\text { Assistive devices }\end{array}$ & Once a year \\
\hline Pediatricians & $\begin{array}{l}\text { Diagnosis and subtype } \\
\text { Etiology } \\
\text { Other health conditions/disabilities }\end{array}$ & Once $^{b}$ \\
\hline
\end{tabular}

Notes: ${ }^{a}$ Examination of the hips is performed once a year for children at GMFCS levels III-V until the age of 8 years. Examination of the spine is based on spinal

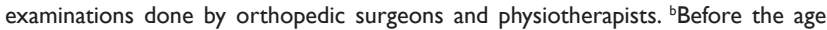
of 5 years.

Abbreviation: GMFCS, Gross Motor Function Classification System.

\section{Quality indicators}

The Statens Serum Institut, a public enterprise under the Danish Ministry of Health, has officially approved six indicators of quality of processes and results of health care. The indicators were developed based on scientific literature, documented best practices from the clinical databases in Sweden and Norway, and consensus in the steering committee.

The quality indicators and results reported in the annual report of 2014 are described in Table 2. The proportion of participants with missing data on variables that are used to calculate indicators 1,5 , and 6 will be reported in the annual report of 2015 and onward. The quality indicators are primarily based on four main variables: radiographic examination of the hip, gross motor function, manual ability, and diagnosis. The clinical importance of the variables varies, and the goal is to report all the four variables in $60 \%$ of participants, if relevant. In the annual report from 2014, $52 \%$ of the participants had all four variables reported, if relevant.

\section{Follow-up}

The follow-up period for the individual child will be from diagnosis, which is typically between birth and 3 years of age, until the child is 15 years of age.

\section{Examples of research}

The regional database has been used to describe the epidemiology of CP in Southern Denmark. ${ }^{8}$ The use of CPOP in several countries makes it possible to compare the quality
Table 2 Quality indicators

Number, name, description, standard, and results $(95 \% \mathrm{Cl})$

I. Radiographic examination of the hips

Type

The proportion of children where the migration percentage for both hips is reported in children at GMFCS levels III-V, age $0-8$ years.

The standard is minimum $90 \%$. The overall result in 2014 was $62 \%$ (95\% Cl: $5 \mathrm{I}-7 \mathrm{I})$

2. Gross motor function

Process

The proportion of children where gross motor function is reported with the GMFCS.

The standard is minimum $95 \%$. The overall result in 2014 was $84 \%$ (95\% Cl: $81-88)$

3. Manual ability

Process

The proportion of children where manual ability is reported with the MACS.

The standard is minimum $75 \%$. The overall result in 2014 was $63 \%$ (95\% Cl: 59-68)

4. Diagnosis

The proportion of children where the diagnosis is confirmed by the pediatrician in children aged 5 years or older.

The standard is minimum $95 \%$. The overall result in 2014 was $88 \%$ (95\% Cl: 84-92)

5. All-or-none

Process

The proportion of children where indicator I-4 is fulfilled, if relevant.

The standard is minimum $60 \%$. The overall result in 2014 was $52 \%$ (95\% Cl: 47-57)

6. Hip dislocation

Result The proportion of children with hip dislocation defined as a migration percentage of $100 \%$ on one or both hips, in children at GMFCS levels III-V, age $0-8$ years.

The standard is maximum $5 \%$. The overall result in 2014 was $6 \%$ (95\% Cl: $2-14)$

Abbreviations: $\mathrm{Cl}$, confidence interval; GMFCS, Gross Motor Function Classification System; MACS, Manual Ability Classification System.

of health care between the participating countries. The data from the follow-up program and database in Sweden have been published in a number of international scientific journals..$^{5,6,9-11}$ The main studies document characteristics of the population and the effects of the follow-up program and database on prevention of dislocation of the hip in children with CP. ${ }^{5,10}$ Results from the first 10 years were published in 2005, and from the first 20 years in 2014. ${ }^{5,10}$ These results have shown a decrease in the incidence of dislocation of the hip from $8 \%$ in a historical control group to $0.5 \%$ in the group that participated in $\mathrm{CPOP}^{5}$

\section{Administrative issues and funding}

Implementation of CPOP has been supported by a private foundation: The Ludvig and Sara Elsass Foundation. Each of the five regions in Denmark is responsible for the implementation and continued operation of the follow-up program, 
which involves health care professionals across regions and municipalities. The database is currently being established as a national clinical quality database and is financially supported by The Danish Clinical Registries. The database is led by a board consisting of representatives from the patient organization, professional associations, the regions, and Danish Clinical Registries.

\section{Conclusion}

The CPOP is currently being developed as a national clinical database in Denmark.

Previous research studies have documented the effects of the follow-up program and database on the prevention of dislocation of the hip in children with CP in Sweden. The objective of the follow-up program is to prevent complications of $\mathrm{CP}$, and the database aims to document, monitor, and improve the quality of health care for children with $\mathrm{CP}$ in Denmark. Studies from Sweden substantiate the potential with regard to research in prevalence, clinical characteristics of the population, and the effects of prevention and treatment.

\section{Acknowledgments}

The Danish CPOP would like to thank the Ludvig and Sara Elsass Foundation for their support and our colleagues for help during the implementation of CPOP in Denmark. This paper was funded by the Program for Clinical Research Infrastructure established by the Lundbeck Foundation and the Novo Nordisk Foundation, and administered by the Danish Regions.

\section{Author contributions}

HMR prepared the manuscript. KNN, BMM, MJ, NE, CRP, GR, HE, and NWP have contributed to critical revision of the manuscript for important intellectual content. All authors contributed toward data analysis, drafting and critically revising the paper and agree to be accountable for all aspects of the work.

\section{Disclosure}

The authors report no conflicts of interest in this work.

\section{References}

1. Ravn SH, Flachs EM, Uldall P. Cerebral palsy in eastern Denmark: declining birth prevalence but increasing numbers of unilateral cerebral palsy in birth year period 1986-1998. Eur J Paediatr Neurol. 2010;14(3):214-218.

2. Surveillance of Cerebral Palsy in Europe. Surveillance of cerebral palsy in Europe: a collaboration of cerebral palsy surveys and registers. Dev Med Child Neurol. 2000;42(12):816-824.

3. Rosenbaum PL, Palisano RJ, Bartlett DJ, Galuppi BE, Russell DJ. Development of the gross motor function classification system for cerebral palsy. Dev Med Child Neurol. 2008;50(4):249-253.

4. Eliasson AC, Krumlinde-Sundholm L, Rosblad B, et al. The manual ability classification system (MACS) for children with cerebral palsy: scale development and evidence of validity and reliability. Dev Med Child Neurol. 2006;48(7):549-554.

5. Hagglund G, Andersson S, Duppe H, Lauge-Pedersen H, Nordmark E, Westbom L. Prevention of dislocation of the hip in children with cerebral palsy - the first ten years of a population-based prevention programme. J Bone Joint Surg Br. 2005;87B(1):95-101.

6. Alriksson-Schmidt A, Hagglund G, Rodby-Bousquet E, Westbom L. Follow-up of individuals with cerebral palsy through the transition years and description of adult life: the Swedish experience. J Pediatr Rehabil Med. 2014;7(1):53-61.

7. Reimers J. The stability of the hip in children. A radiological study of the results of muscle surgery in cerebral palsy. Acta Orthop Scand Suppl. 1980;184:1-100.

8. Froslev-Friis C, Dunkhase-Heinl U, Andersen JD, Stausbol-Gron B, Hansen AV, Garne E. Epidemiology of cerebral palsy in Southern Denmark. Dan Med J. 2015;62(1):A4990.

9. Hagglund G, Andersson S, Duppe H, Lauge-Pedersen H, Nordmark E, Westbom L. Prevention of severe contractures might replace multilevel surgery in cerebral palsy: results of a population-based health care programme and new techniques to reduce spasticity. J Pediatr Orthop B. 2005;14(4):269-273.

10. Hagglund G, Alriksson-Schmidt A, Lauge-Pedersen H, RodbyBousquet E, Wagner P, Westbom L. Prevention of dislocation of the hip in children with cerebral palsy: 20-year results of a population-based prevention programme. Bone Joint J. 2014;96-B(11):1546-1552.

11. Westbom L, Hagglund G, Nordmark E. Cerebral palsy in a total population of 4-11 year olds in southern Sweden. Prevalence and distribution according to different $\mathrm{CP}$ classification systems. BMC Pediatr. 2007;7:41.
Clinical Epidemiology

\section{Publish your work in this journal}

Clinical Epidemiology is an international, peer-reviewed, open access, online journal focusing on disease and drug epidemiology, identification of risk factors and screening procedures to develop optimal preventative initiatives and programs. Specific topics include: diagnosis, prognosis, treatment, screening, prevention, risk factor modification,

\section{Dovepress}

systematic reviews, risk \& safety of medical interventions, epidemiology \& biostatistical methods, and evaluation of guidelines, translational medicine, health policies \& economic evaluations. The manuscript management system is completely online and includes a very quick and fair peer-review system, which is all easy to use. 